\title{
FOLKSONOMIAS, REDES SOCIAIS E A FORMAÇÃO PARA O TAGGING LITERACY: DESAFIOS PARA A ORGANIZAÇÃO DA INFORMAÇÃO EM AMBIENTES COLABORATIVOS VIRTUAIS
}

\author{
FOLCSONOMÍAS, REDES SOCIALES Y LA FORMACIÓN PARA EL \\ TAGGING LITERACY: RETOS PARA LA ORGANIZACIÓN DE LA \\ INFORMACIÓN EN AMBIENTES COLABORATIVOS VIRTUALES
}

\begin{abstract}
Maria Aparecida Moura - mamoura@eci.ufmg.br
Professora Adjunta da Escola de Ciência da Informação da Universidade Federal de Minas Gerais.

Doutora em Comunicação e Semiótica pela PUC de São Paulo.

Coordenadora do Núcleo de Estudos das Mediações e Usos Sociais dos Saberes e Informações em Ambientes Digitais (NEMUSAD).
\end{abstract}

\begin{abstract}
Resumo
O uso combinado dos sistemas de etiquetagem social (social tagging), da personalização tecnológica bem como do funcionamento colaborativo em redes sociais trouxe novos desafios à organização e à recuperação da informação contemporânea em ambientes colaborativos virtuais. Esses desafios estão, sobretudo, na alteração da mediação na organização e acesso à informação, hoje exercida e compartilhada de modo dinâmico pelos usuários finais por meio de um conjunto de camadas tecnológicas. Neste artigo, analisam-se as implicações sociais e técnicas dos fatores intervenientes, notadamente as folksonomias e a personalização tecnológica, na organização da informação e do conhecimento em ambientes colaborativos. Sistematizam-se os acordos estabelecidos nos processos de organização da informação e recuperação da informação em ambientes colaborativos abertos. Apresentam-se os conceitos de identidade informacional, ambientes virtuais de trocas e culturas informacionais e o conceito de cultura classificatória (tagging literacy) que compreende as questões do usuário, na condição de ator principal na especificação de necessidades informacionais.
\end{abstract}

\section{Palavras-chave}

Organização da Informação; Competência Classificatória; Folksonomias; Redes Sociais; Ambientes Colaborativos. 


\section{INTRODUÇÃO}

O advento da web 2.0 tornou possível a redução de distintos intermediários no acesso à informação em ambientes digitais. Nesses ambientes verifica-se a sobreposição de atores sociais na efetivação de múltiplos papéis que são exercidos por intermédio de identidades informacionais autônomas, oportunizadas pela intensificação dos fluxos informacionais e pela redução paulatina da sociabilidade contemporânea a interfaces eletrônicas.

A identidade, compreendida nos termos da tradição sociológica do interacionismo simbólico, estabelece vínculos fundamentais com o mundo social vivido através das mediações da comunicação e da linguagem. Assim, considera-se que as identidades individuais são fortemente demarcadas pela cultura na qual os sujeitos encontram-se imersos. Contudo, a hipermodernidade, que caracteriza nosso contexto de análise, ampliou os espaços para a vivência e expressão do indivíduo. Além disso, permitiu que a identidade pudesse ser atualizada em função da individualidade, da autocompreensão, da flexibilidade e da diferença.

Desse modo, os novos alinhamentos permitidos pelos ambientes digitais criaram o cenário propício para a experimentação da identidade pautada pela informação obtida na descrição fornecida pelo sujeito social em situação de interação ou pelo rastreamento dos traços que evidenciam os percursos informacionais realizados no ciberespaço.

Em virtude disso, pode-se afirmar que vivemos em mundo simultaneamente real e virtual, demarcado pela individualidade, a sociabilidade $e$ pelas redes sociais de cooperação e produção nuançadas pela presença-ausente favorecida pelas tecnologias digitais. Nesse contexto, estamos cada vez mais acessíveis e mergulhados em uma aparente sensação de que todas as "relevâncias do mundo" estão ao alcance de nossas próteses tecnológicas.

Constata-se que parte das interações desenvolvidas no mundo real guarda alguma referência com os agenciamentos identitários de caráter informacional, circunstância em que o sujeito social dilui-se em fluxos e identifica-se e/ou provoca identificações de caráter informacional que repercutem no mundo da vida.

Esse contexto é integrado também pelas redes sociais que de acordo com Santos (2002) funcionam como suportes corpóreos do cotidiano. Nesse sentido, caracterizam-se como toda infra-estrutura que permite "o transporte de matéria, de energia ou de informação, e que se inscreve sobre o território onde se caracteriza pela topologia dos 
seus arcos de transmissão, seus nós de bifurcação ou de comunicação." (N. CURIEN apud SANTOS, 2002, p. 262).

As redes sociais incorporam, de acordo com Marteleto (2005), três dimensões fundamentais: a dimensão sócio-comunicacional, a lingüístico-discursiva e a produção de sentidos.

A dimensão sócio-comunicacional envolve os elos, as motivações e as interações entre os atores sociais. A dimensão linguística e discursiva incorpora os aspectos cognitivos e informacionais envolvidos no compartilhamento social. Finalmente, a dimensão da produção de sentidos explicita o fluxo e a dinâmica da ação colaborativa partilhada.

Desnecessário assinalar as inúmeras complexidades que o conceito de identidade informacional em rede trouxe aos processos de organização da informação. Se antes os instrumentos e métodos de organização da informação norteavam-se por sujeitos concretos, hoje se tornou necessário compreender mais amplamente a dinâmica de interação entre os fluxos informacionais que se realizam na web.

Parece inegável que as possibilidades técnicas inauguradas pelas inovações incidiram decisivamente nas relações entre os sujeitos. Com o advento da cibercultura tornou-se possível, por exemplo, a efetivação de ações de natureza coletiva com participação de sujeitos geograficamente dispersos. A chave que permite o encontro entre tais subjetividades deixou de ser a empatia fundada nas relações interpessoais para efetivar-se pela convergência aparente de perfis numéricos e as evidências da similaridade de interesses demarcada pelos vestígios eletrônicos, um fio de Ariadne contemporâneo.

O ciberespaço promove e intensifica a efetivação de uma singularidade ordinária e avessa às tentativas de centralização, nele é possível escolher um personagem, uma vida - "[...] mascaras de agir como um nômade nas diversas subjetividades prêt-à-porter da sociedade contemporânea." (LEMOS, 2000, p.90).

Na base dessas transformações está a fluidez informacional tornada possível pela digitalização da informação. Os fluxos se constituem, de acordo com Santos (2002, p. 276) na realização conjunta de três possibilidades provindas da existência de formas perfeitas universais (fruto da nova evolução técnica - informação tornada ubíqua e instantânea), das normas universais e da informação universal (base para um discurso 
universal). A fluidez informacional foi facilitada em grande medida pela unicidade técnica, a interdependência funcional, a unicidade e convergência dos momentos e pela ampliação da circulação da informação pragmática (operacional). Desse modo, a fluidez é ao mesmo tempo, uma causa, uma condição e um resultado dos fenômenos que testemunhamos na atualidade.

A partir das alterações ocorridas na materialidade textual, teve início o apagamento de um dos critérios que nos permitia distinguir, hierarquizar e classificar os discursos disseminados: o suporte físico. O formato eletrônico, ao relativizar o papel do suporte, rompeu com as possibilidades de identificação das unidades textuais a partir da forma, passando a exigir novas habilidades tanto para construir os discursos quanto para assimilá-los.

Nesse contexto, as trocas informacionais deixaram de se realizar exclusivamente em ambientes destinados a esse fim e passaram a contar com diversificação de espaços, com a sobreposição de mediadores e o remodelamento da cultural informacional que emana dessas novas práticas.

Tais inovações abriram o caminho para a constituição de ambientes virtuais de trocas e culturas informacionais, um "não-lugar", no qual os sujeitos interagem e negociam através da publicidade de seus perfis e hábitos de informação. Nesses espaços informacionais os sujeitos manifestam-se como fluxo informacional e atuam para além da rigidez do corpo, circunstancialmente perene e concreto.

Nesse trabalho busca-se compreender as implicações sociais e técnicas desses novos agenciamentos para a organização da informação em ambientes digitais. Para tanto, serão apresentados os conceitos de ambientes virtuais de troca e culturas informacionais e de competência classificatória (tagging literacy). Por fim, será discutida a efetividade de acordos em torno das linguagens adotadas em ambientes digitais em direção à personalização do acesso a informação em sistemas informacionais contemporâneos.

\section{A ORGANIZAÇÃO DA INFORMAÇÃO EM AMBIENTES COOPERATIVOS}

A personalização tecnológica, proporcionada pela web 2.0, abriu novas possibilidades para o desenvolvimento de produtos e serviços agregados e ampliaram a presença do usuário comum na coordenação de ações de produção, organização e 
difusão de informações voltadas a públicos segmentados pela natureza das redes sociais aos quais pertencem.

A segmentação alcançada decorre das possibilidades de modelagem da linguagem natural para fins de representação e recuperação da informação em ambientes virtuais de trocas e culturas informacionais.

Qin (2008) assinala que esses novos ambientes podem ser considerados espaços sociais semânticos nos quais se identifica a co-existência de comunidades especializadas que se organizam em torno do compartilhamento de informações através de tópicos e conceitos relevantes.

Esses espaços semânticos são randomicamente criados por usuários autônomos que compartilham diferentes padrões de qualidade da informação e distintas visões de mundo.

Nesse sentido, o modelo proposto por Qin (2008) apresenta-se como uma síntese circular composta por agentes comunicacionais humanos, uma rede de conceitos e um conjunto de tags.

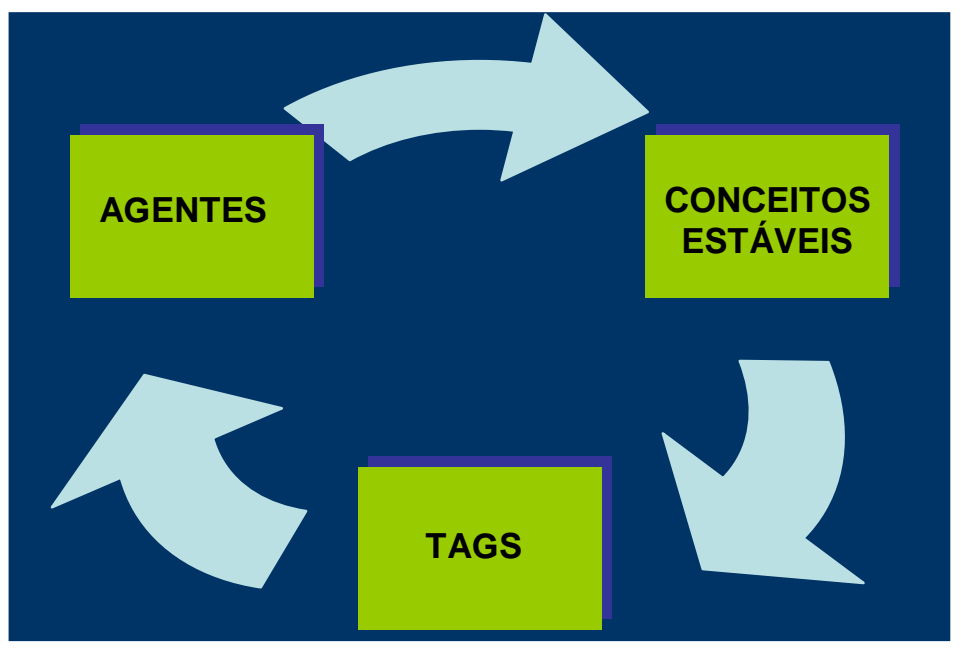

Figura 1 - Modelo Agente-Tag-Conceito (espaços sociais semânticos)

Fonte: Qin ( 2008)

Para o autor, as tags (etiquetas) são a base dos espaços sociais semânticos e podem ser estudadas em função das palavras (linguística), dos símbolos programáticos (Ciência da Computação), das significações (Semiótica e Psicologia), da lógica simbólica (Filosofia), dos metadados (Biblioteconomia e Ciência da Informação).

No contexto da Ciência da informação é possível constatar que, como assinala Qin (2008), existem algumas diferenças entre o modelo formal de organização do conhecimento e os atuais espaços sociais semânticos. Os espaços sociais semânticos, 
por se configuraram em torno de práticas informacionais do usuário final, organizam-se em estruturas intuitivas nas quais a distinção entre conceitos estáveis e tags não são tomados como elementos fundamentais. Nesse aspecto, tendem a se tornarem espaços especializados em virtude da sofisticação contextual que os organiza. Na tabela abaixo são apresentados as principais distinções entre os dois modelos.

\begin{tabular}{|c|c|}
\hline ESPAÇOS SOCIAIS SEMÂNTICOS & ORGANIZAÇÃO DA INFORMAÇÃO \\
\hline $\begin{array}{l}\text { Agregação de conhecimento empírico e } \\
\text { racional convivendo em um mesmo espaço e } \\
\text { sem hierarquias aparentes, }\end{array}$ & Conhecimen \\
\hline $\begin{array}{l}\text { Representação empírica dos objetos de } \\
\text { informação, }\end{array}$ & $\begin{array}{l}\text { Representação racional do } \\
\text { conhecimento em objetos de informação, }\end{array}$ \\
\hline $\begin{array}{l}\text { A recuperação da informação é dependente } \\
\text { da experiência prévia do usuário, }\end{array}$ & $\begin{array}{l}\text { A recuperação da informação tem uma } \\
\text { abordagem controlada, }\end{array}$ \\
\hline Sofisticação contextual, & Expressão formal de conceitos, \\
\hline $\begin{array}{l}\text { Articulação simultânea de conceitos e tags } \\
\text { em um mesmo espaço. }\end{array}$ & $\begin{array}{l}\text { Relações intelectuais e dedutivas entre } \\
\text { conceitos. }\end{array}$ \\
\hline
\end{tabular}

Tabela 1 - Distinção entre espaços sociais semânticos e a organização tradicional da informação ${ }^{1}$

A alta densidade no compartilhamento de determinadas tags pode revelar tendências e parcerias semânticas num dado domínio ou mesmo ontologias emergentes (MIKA, 2005; QIN, 2008). Nesse sentido, acredita-se que a interpenetração existente entre os dois modelos pode contribuir para o aprimoramento da linguagem, seja na melhoria dos processos de validação semântica ou na avaliação da performance do instrumento de representação verbal proposto.

Nesses termos, Qin (2008) assinala que num futuro próximo a articulação entre os espaços tradicionais e os sociais poderá trazer como benefício a incorporação mais ágil do vocabulário, das estruturas e das relações entre os termos novos, a extração automática de ontologias leves, o provimento de inteligência aos métodos estatísticos e a utilização combinada de recursos léxicos, comunidades baseadas em recursos semânticos e controle de vocabulário.

\footnotetext{
${ }^{1}$ Baseado em Qin (2008).
} 
Para tanto, o autor propõe um modelo de identificação de relacionamentos entre tags no qual propõe a articulação entre algoritmos para inferir e extrair relações entre tags em seus contextos. Conforme modelo apresentado na figura 2.

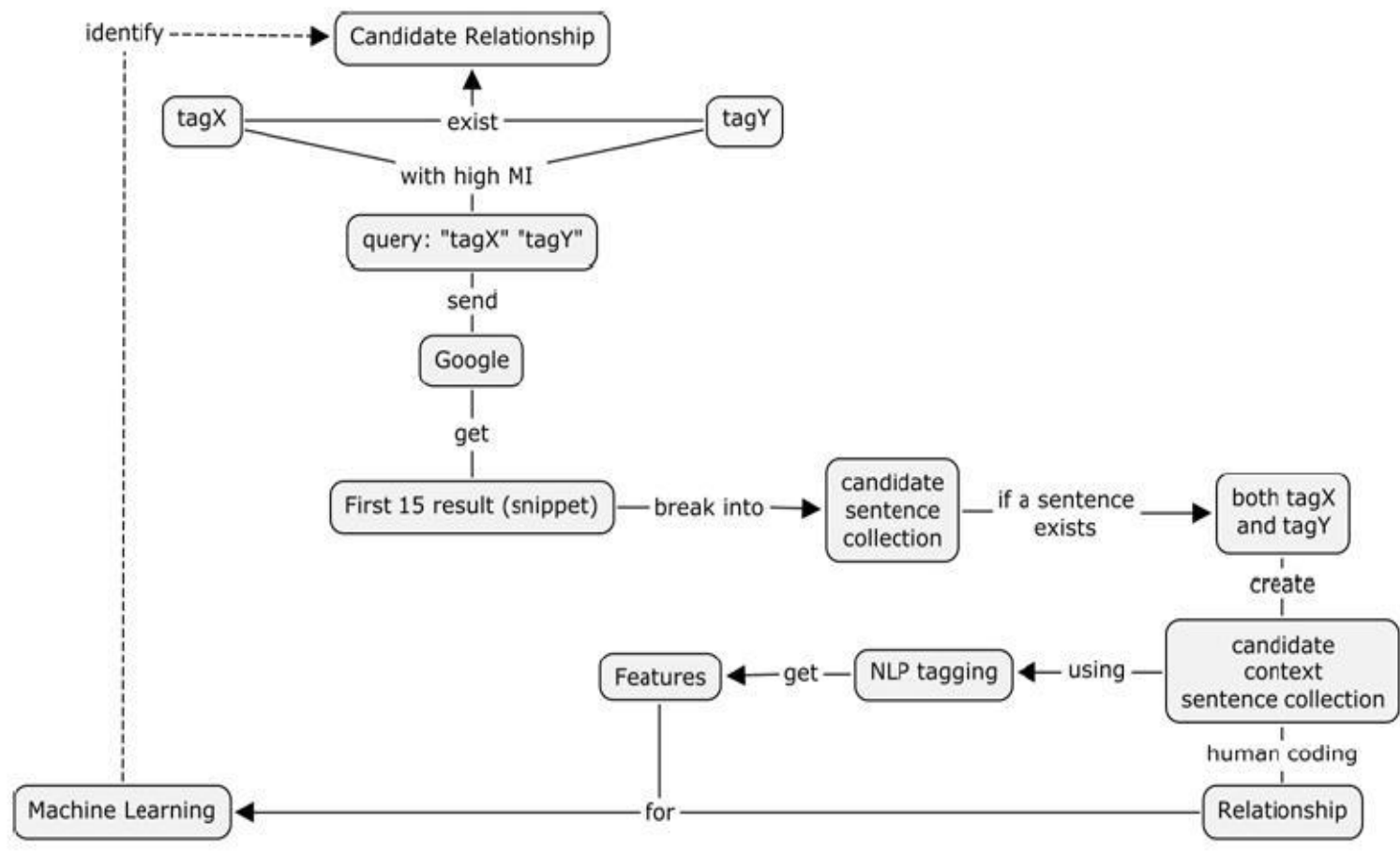

Figura 2 - Modelo de identificação de relações entre tags

Fonte: QIN; CHEN; LIU (2008)

Todavia, tendo em vista a herança histórica e as contribuições dos sistemas bibliográficos tradicionais, Svenonious (2000) enfatiza a necessidade de equilíbrio na adoção da linguagem natural nos novos contextos.

É instrutivo - especialmente tendo em conta o interesse recente e atividade voltada para organizar a informação digital - compreender certas características dos sistemas tradicionais bibliográficos. Dois aspectos, em particular, devem ser considerados. Um refere-se ao fato desses sistemas fornecerem soluções para os problemas que obstruem o acesso eficiente à informação. Ainda hoje alguns problemas são causados pelo acesso as novas tecnologias, outros - decorrem da variedade de informações, das múltiplas facetas dos usuários e das anomalias que caracterizam a linguagem adotada na recuperação da informação. (SVENONIOUS, 2000, p.2).

Cunhado por Vander Wal's, o conceito de folksonomia se refere na origem ao esforço de integração do usuário final na especificação da informação de uso pessoal. Um de seus elementos centrais é a perspectiva bottom-up que orienta o consenso construído entre os usuários. Nesse sentido, a folksonomia pode ser compreendida como: 
O resultado da livre codificação de informação e objetos (qualquer coisa com um URL) para a própria recuperação. A marcação é feita em um ambiente social (compartilhado e aberto a outros). A atividade de codificação é feito pela pessoa que consome as informações. (WAL's, 2009). ${ }^{2}$

As folksonomias contribuíram enormemente para a popularização de novas perspectivas de classificação de documentos digitais e ampliaram as possibilidades de compartilhamento de novas significações para termos e conceitos socialmente estabelecidos e debatidos em ambientes virtuais.

No caso específico do Twine (http://www.twine.com), por exemplo, o usuário pode conhecer informações vinculadas ao seu interesse específico, armazenar e compartilhar informações em distintos formatos e receber recomendações baseadas em seus interesses. Para tanto, o sistema emprega o processamento da linguagem natural e a inteligência artificial para extrair conceitos dos dados disponibilizados pelos usuários.

Nesse sistema o usuário pode colaborar através da manutenção de coleções organizadas (twine) por tópicos especializados. Essas coleções podem ser privadas ou públicas. Quando públicas, elas dão origem a comunidades temáticas nas quais as possibilidade de especificação, compartilhamento e gestão da metalinguagem de referência se tornam mais efetivos.

Quintarelli (2005) afirma que a grande contribuição da folksonomia nos contextos de organização da informação está na possibilidade de agregação de informações nos ambientes distribuídos que o instrumento enseja.

Para o autor, as principais características das folksonomias são: a explicitação em relação aos padrões de comportamento do usuário, a agregação das linguagens e dos fluxos de interação, a produção de benefícios para os usuários envolvidos e a relevância em relação aos propósitos do site. Isso se deve, em grande medida, ao surgimento dos Sistemas de Classificação Distribuída (Distributed Classification Systems -DCSs) tais como o Delicious (http://delicious.com), o Flickr (http://www.flickr.com), o Faviki (http://www.faviki.com), o Twine (http://www.twine.com), dentre outros. Nos ambientes providos por tais sistemas, a classificação temática é realizada com o apoio de esquemas classificatórios determinados pelos próprios usuários.

\footnotetext{
2 "Folksonomy is the result of personal free tagging of information and objects (anything with a URL) for one's own retrieval. The tagging is done in a social environment (shared and open to others). The act of tagging is done by the person consuming the information". WAL'S, Vander. Folksonomy. Disponível em: <http://www.vanderwal.net/folksonomy.html>. Acesso em: 20. abr. 2009.
} 
Entretanto, os códigos adotados pelos DCSs, ao reduzirem a necessidade de negociação formal dos significados das tags para público a que se destina, tornaram ainda mais complexo a tarefa de indexar informações em contextos digitais, pois, em tese, a classificação tornou-se um produto de orientação self-service.

Parte integrante desse contexto de análise, as atuais estratégias de marketing eletrônico têm como foco de intervenção a interação dos sujeitos através de suas redes sociais. No caso particular das estratégias de marketing, o principal interesse é conhecer a manifestação lingüística das redes sociais com vistas a aprimorar a oferta de produtos de valor adicionado.

Um exemplo desse tipo de estratégia é o agregador de redes sociais Ning (www.ning.com), uma plataforma on-line gratuita para a criação e a gestão de redes sociais personalizadas. Criada em outubro de 2004, o Ning conta hoje com cerca de 230 mil redes sociais oriundas de 176 países.

O grande trunfo desse tipo de ferramenta no que concerne à organização da informação refere-se à oferta de plataformas on-line interativas (ambientes de troca e de culturas informacionais) que permitam a livre manifestação das identidades informacionais na disponibilização e oferta de conteúdos especializados.

Desse modo, as busswords (palavras ou conceitos em evidência), amplamente manipuladas pelas identidades informacionais nos espaços virtuais, tornaram-se também um foco de interesse para o campo da Ciência da informação. Isso se deve ao caráter enunciativo e inovador, em termos do vocabulário adotado pelas redes especializadas no contexto digital.

Assim, concordamos com Quintarelli (2005) quando o mesmo assinala que as folksonomias podem trazer contribuições aos estudos da organização da informação em $\mathrm{Cl}$ devido a fato de surgirem como um meio de auto-expressão de um grupo e, em um contexto mais geral, sugerirem possibilidades de agregação, de análise e do funcionamento de comunidades que podem acelerar o compartilhamento e a especificação de linguagens de referência. 


\section{A CONSTITUIÇÃO DO TAGGING LITERACY E A EFETIVAÇÃO DE LINGUAGENS DE REFERÊNCIA EM AMBIENTES COLABORATIVOS}

Os principais interesses da Ciência da Informação, ao estudar a folksonomia como manifestação orgânica do linguajar que emana das identidades informacionais, residem na necessidade de compreender e dimensionar os desdobramentos da participação dos usuários na constituição de linguagens de referência adotadas na organização e recuperação da informação em ambientes digitais. É preciso compreender ainda a dinâmica de constituição dos acordos que legitimam a terminologia adotada em tais ambientes, anteriormente exercida pelas garantias literária, de uso e estrutural.

Nesses termos, indaga-se sobre o caráter discursivo e semiótico que orienta a constituição da linguagem nesses ambientes. É possível falar em autoridade semântico ou semiótica? Que novas abordagens metodológicas podem derivar desses novos arranjos informacionais?

Preocupado com o desdobramento e o impacto social da atividade de classificação social na descrição e recuperação da informação Ulises Mejias (2005) propõe uma formação humana para a atividade classificatória em ambientes digitais (tagging literacy TL). O tagging literacy consiste na sensibilização e formação humana para o desenvolvimento de atividades de classificação da informação e do conhecimento em ambientes colaborativos digitais.

Acredita-se que, dado ao caráter incontornável da ação direta do usuário na disponibilização e organização de conteúdos em ambientes digitais, tornou-se condição sine qua non que a Ciência da Informação se ocupe da constituição de um plano de formação humana voltado a esse contexto. Sobretudo, porque embora os sistemas DCSs não pareçam almejar substituir os motores de busca, parece necessário compreender os seus desdobramentos e impactos para o compartilhamento coletivo da informação e do conhecimento.

Ulises Mejias (2005) sugere algumas ações que podem ampliar a qualidade semântica das tags e contribuir na performance dos usuários que atuam com indexadores sociais. Acreditamos que tais sugestões podem vir a contribuir na consolidação de um plano formativo para esse novo contexto de ação da Cl. Sintetizamos no quadro abaixo as principais características da proposta. 


\begin{tabular}{|c|c|c|}
\hline CARACTERISTICA & ORIENTAÇÃO & MODELO SEMÄNTICO \\
\hline $\begin{array}{l}\text { Composição de tags de } \\
\text { significação pessoal, mas } \\
\text { que possam ensejar a } \\
\text { adoção coletiva. }\end{array}$ & Eleger tags que possam servir a ambos os propósitos. & $\begin{array}{l}\text { Acompanhamento, perenização e } \\
\text { controle semântico das tags } \\
\text { propostas. }\end{array}$ \\
\hline $\begin{array}{l}\text { Uso de plural para definir } \\
\text { categorias }\end{array}$ & $\begin{array}{l}\text { Estabelecer convenções na distinção entre de classes ou } \\
\text { subclasses. }\end{array}$ & Blogs, árvores. \\
\hline $\begin{array}{l}\text { Uso de qualificadores para } \\
\text { desambigüisar os termos. }\end{array}$ & $\begin{array}{l}\text { O uso de termos qualificadores que permitam identificar o campo } \\
\text { semântico da tag. }\end{array}$ & $\begin{array}{l}\text { Manga (fruta) } \\
\text { Manga (parte de uma peça do } \\
\text { vestuário) }\end{array}$ \\
\hline O uso de siglas & $\begin{array}{l}\text { Reduzir o número de siglas e acrônimos que podem dificultar a } \\
\text { compreensão do campo semântico ao qual a tag se aplica. Adotá- } \\
\text { los quando se constituírem em marcas socialmente reconhecidas. }\end{array}$ & \\
\hline Tags específicas e gerais & $\begin{array}{l}\text { Embora as tags se orientem para a descrição dos objetos em sua } \\
\text { especificidade, verifica-se que privilegiar também as tags gerais, } \\
\text { pode facilitar a adoção coletiva das mesmas. }\end{array}$ & Árvores frutíferas - macieira \\
\hline Controle de idiossincrasias & $\begin{array}{l}\text { Embora os ambientes de classificação social sejam propícios à } \\
\text { manifestação da idiossincrasia, sugere-se o monitoramento } \\
\text { pessoal das mesmas para ampliar a recuperação dos conteúdos } \\
\text { classificados. Sobretudo porque, um mesmo o classificador social } \\
\text { poderá ter dificuldades futuras com grandes massas de tags que } \\
\text { já não fazem o mesmo sentido que o orientou na circunstância da } \\
\text { classificação. }\end{array}$ & $\begin{array}{l}\text { No lugar de urso incrível } \\
\text { Adote urso panda, urso polar, } \\
\text { urso pardo. }\end{array}$ \\
\hline Adoção de tags compostas & $\begin{array}{l}\text { Verificar as possibilidades que a DCSs oferecem para a } \\
\text { incorporação de tags compostas, pois o uso excessivo de tags } \\
\text { simples pode gerar recuperação de informações espúrias ou } \\
\text { indesejadas. }\end{array}$ & $\begin{array}{l}\text { Adote, se possível: Música } \\
\text { clássica (melhor opção), ou } \\
\text { musicaclassica ou música- } \\
\text { clássica } \\
\text { Evite: música, clássica. (tags } \\
\text { muito genéricas). }\end{array}$ \\
\hline $\begin{array}{l}\text { Observação das normas da } \\
\text { rede }\end{array}$ & $\begin{array}{l}\text { Identifique, incorpore e sugira normas para o bom funcionamento } \\
\text { dos DCSs. }\end{array}$ & $\begin{array}{l}\text { Ao iniciar o uso de um DCSs é } \\
\text { preciso conhecer suas } \\
\text { funcionalidades e a articulação } \\
\text { das mesmas com as suas } \\
\text { necessidades específicas. }\end{array}$ \\
\hline $\begin{array}{l}\text { Contribuição } \text { para a } \\
\text { manutenção dos esforços } \\
\text { coletivos }\end{array}$ & $\begin{array}{l}\text { Considerando-se a máxima de que "lixo dentro implica em lixo } \\
\text { fora" é preciso monitorar sempre os espaços individuais dentro do } \\
\text { DCSs para que erros de grafia, estrangeirismos ou } \\
\text { categorizações equivocadas não dificultem o funcionamento do } \\
\text { empreendimento coletivo representado por esses ambientes. }\end{array}$ & $\begin{array}{l}\text { Criação de acordos entre os } \\
\text { sujeitos que adotam a linguagem } \\
\text { de referência proposta pela } \\
\text { comunidade. }\end{array}$ \\
\hline $\begin{array}{l}\text { Acompanhamento das } \\
\text { tendências e divulgação de } \\
\text { etiquetas pessoais contendo } \\
\text { novas abordagens }\end{array}$ & $\begin{array}{l}\text { Criar procedimentos que permitam que a comunidade de } \\
\text { referência possa acompanhar os desdobramentos de um } \\
\text { esquema de indexação pessoal. }\end{array}$ & $\begin{array}{l}\text { Uso de remissivas ou notas de } \\
\text { escopo para enfatizar a } \\
\text { transformação do modelo mental } \\
\text { do indexador social. }\end{array}$ \\
\hline Assinar RSS & $\begin{array}{l}\text { Criar procedimentos automáticos para acompanhar e permitir o } \\
\text { acompanhamento das atualizações da coleção pessoal e da } \\
\text { indexação proposta. }\end{array}$ & $\begin{array}{l}\text { Anexar ferramentas RSS nas } \\
\text { coleções pessoais. }\end{array}$ \\
\hline $\begin{array}{l}\text { Adicionar nas listas } \\
\text { pessoais sujeitos que } \\
\text { tenham perfis próximos ou } \\
\text { complementares aos seus. }\end{array}$ & $\begin{array}{l}\text { Promover a disseminação seletiva da informação tomando por } \\
\text { base o compartilhamento de perfis (identidades) informacionais } \\
\text { comuns. }\end{array}$ & $\begin{array}{l}\text { Pode garantir a qualidade e a } \\
\text { estabilidade da linguagem de } \\
\text { referência compartilhada. }\end{array}$ \\
\hline
\end{tabular}

Quadro 1 - Adaptação complementar ao artigo Tagging Literacy. Disponível em: <http://blog.ulisesmejias.com/2005/04/26/tag-literacy/\#index> 
Os DCSs funcionam como espaços para a modelagem da linguagem e, de acordo com Javier Canadá $^{3}$, são distintas as motivações dos atores sociais em modelar a linguagem em tais ambientes. Ao analisar o movimento do social tagging na web o autor assinala que na base dessa modalidade de cooperação co-existem distintas perspectivas às quais denominou egocêntrica, amigável, altruísta e populista.

A perspectiva egocêntrica orienta-se pela descrição pessoal da informação com vista a sua recuperação futura, sem, contudo, haver uma preocupação com o fato de essa informação poder ser útil a outros sujeitos em distintos contextos sociais. Nesse caso, a indexação realizada funciona como lembretes mnemônicos que revelam o universo semântico de seu criador.

A perspectiva amigável introduz um primeiro nível de colaboração que se manifesta em um acordo de linguagem que é adotado na descrição dos objetos informacionais em contextos digitais. Nesses casos, os parceiros em cooperação pactuam uma linguagem de referência que tem a validade circunscrita ao "círculo íntimo" de compartilhamento.

A perspectiva altruísta também se manifesta no nível da linguagem e incorpora um segundo nível de cooperação. Nessa abordagem os agentes tentam estabelecer alguma regularidade e padronização na adoção das tags, de modo que a recuperação da informação seja mais efetiva e garanta o acesso de uma gama mais ampla de usuários.

A perspectiva populista, por outro lado, busca incorporar o aprendizado da dinâmica colaborativa em rede para ofertar conteúdos comerciais embalados em etiquetas de apelo popular. Nesse sentido, essa perspectiva viabiliza comercialmente o monitoramento das práticas colaborativas na web ao vincularem o universo semântico de determinadas etiquetas à oferta de bens e serviços.

Em virtude das práticas de etiquetagem assinaladas por Cañada, propõe-se modelo explicativo dos acordos de linguagem que se realizam nos ambientes digitais. Para tanto, reporta-se à necessidade de uma "virada semiótica" nos estudos relativos à organização da informação em contextos digitais (MOURA, 2007), por acreditarmos, como González de Gómez e Gracioso (2007, p. 2), que precisamos incluir nos estudos da $\mathrm{Cl}$ novos aportes teóricos que nos permitam compreender o novo cenário informacional, caracterizado, sobretudo, pelo contexto virtual.

\footnotetext{
${ }^{3}$ CAÑADA, J. Tipologias y estilos en el etiquetado social. (2006) Disponível em: <http://www.terremoto.net/tipologias-yestlos-en-el-etiquetado-social/>. Acesso em: 29. mar. 2009.
} 
Os acordos propostos guardam alguma similaridade com a perspectiva triádica do signo semiótico que se refere a três formas de ver o mundo. Em seu esforço de concepção Peirce propôs uma tríade de categorias universais: Firstness (primeiridade), Secondness (secundidade) e Thirdness (terceiridade).

A primeiridade, de acordo com Nöth (1995), corresponde ao sentimento imediato e sem reflexão presente nas coisas. Nesse aspecto, é mera possibilidade irrefletida, algo que vem à mente no instante presente. A secundidade se refere ao movimento de ação $\mathrm{e}$ reação. É uma categoria de relação entre ações, fatos, experiências posicionadas no tempo e espaço. A terceiridade é a categoria da mediação que tem por função relacionar um segundo a um terceiro numa síntese intelectual. Corresponde a inteligibilidade do pensamento em signos.

De acordo com $\mathrm{Mai}^{4}$, a abordagem semiótica é pertinente para compreender os processos de intervenção humana, seja em contextos de manipulação de objetos informacionais concretos ou digitais. De sua perspectiva, a abordagem semiótica de Peirce referente à semiose ilimitada pode nos auxiliar na compreensão da ação do sujeito em situação de interpretação e de tradução intersemiótica empreendida na indexação.

O triângulo semiótico é constituído pelo objeto, pelo signo e o interpretante.

O representamen corresponde ao primeiro correlato de uma relação triádica. Refere-se ao elemento que é dado a conhecer pelo movimento de representação do signo.

O signo media as relações de conhecimento dos homens entre si e com a natureza. É uma intermediação imprescindível visto que, do ponto de vista da semiótica, não é possível o estabelecimento de uma relação direta com o objeto, mas com a sua representação. O signo, nesses termos, ocupa o lugar do objeto.

O interpretante, por seu turno, é o responsável pela dinamização do processo de significação e não deve ser confundido com interpretação. Na realidade, ele é o resultado do processo de produção de sentido realizado ad infinitum pelo sujeito cognitivo. Ele representa um conteúdo objetivo que se depreende da referência que o signo faz a seu objeto na semiose e é apenas nesse aspecto que o mesmo pode ser entendido como uma interpretação. Caracteriza-se como imediato, dinâmico e final.

\footnotetext{
${ }^{4} \mathrm{MAI}$, Jens-Erik. The Concept of Subject in a Semiotic Light. Disponível em: <http://www.asis.org/annual97/mai.htm>. Acesso em:15 out. 2008.
} 
O triângulo folksonômico revela os elementos que compõem o movimento colaborativo em ambientes de troca e cultura informacional. São eles: os recursos informacionais, os agentes humanos (por vezes, vistos como identidades informacionais em fluxo) e as tags adotadas para descrever os conteúdos.

É possível encontrar referências pertinentes entre o triângulo semiótico e o triângulo folksonômico. Contudo, é necessário ponderar que a tríade semiótica de Peirce revela processos mentais mais sofisticados, dentre os quais o triângulo folksonômico configura-se apenas como uma evidência.

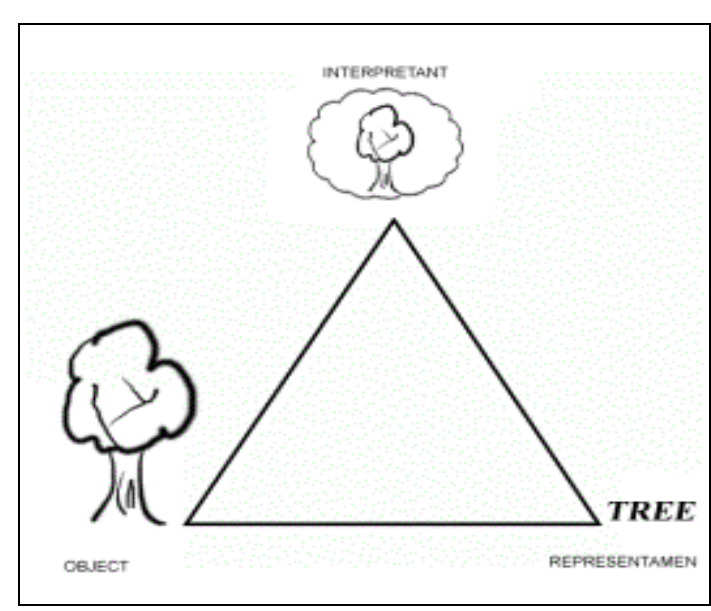

Triângulo semiótico

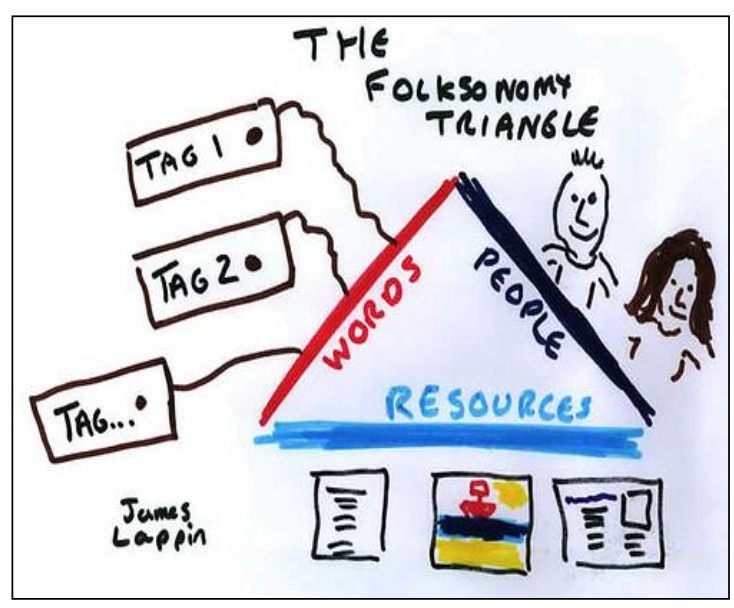

Triângulo folksonômico

Figura 3 - Triângulos semiótico e folksonômico.

Fontes: < http://www.ludology.org/articles/thesis/ThesisOPPRESSED_files/image003.gif>, <http://scot-project.org/2007/04/03/the-folksonomy-triangle/>

A semiose ilimitada representada no triangulo da semiose (fig. 3) evidencia o movimento ad infinitum do processo de significação, uma característica indiscutível dos processos de indexação social. 


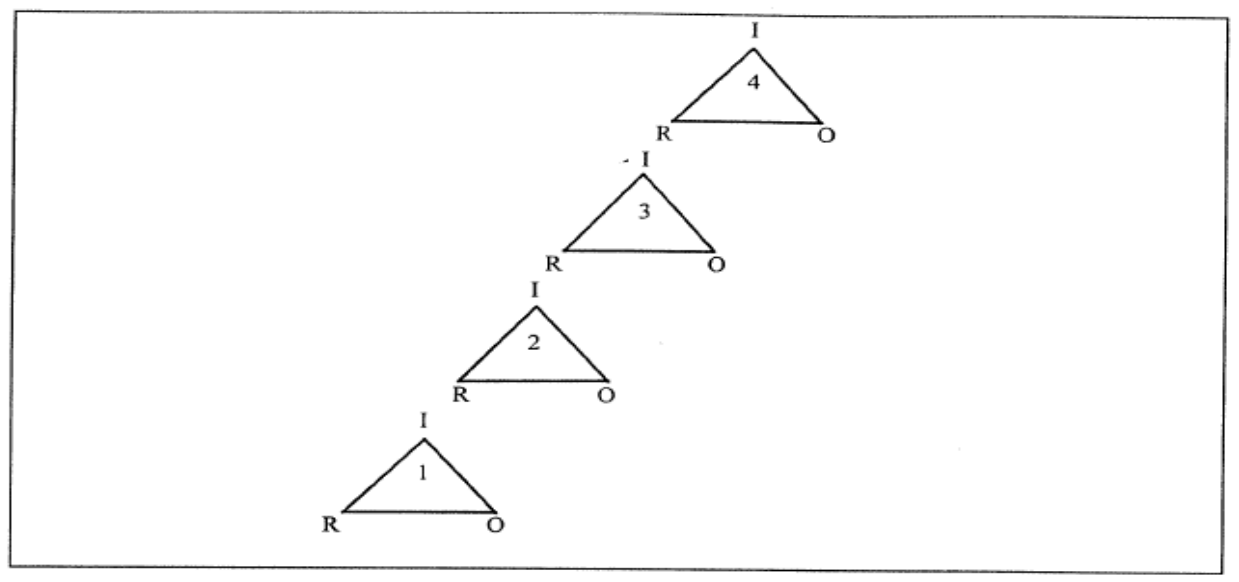

Figura 4 - Triângulo da semiose ilimitada (MAI, 2008).

Tendo em vista, a ponderação apresentada por Mai e à luz da reflexão proposta por Peirce, sugerimos no quadro abaixo, a possibilidade de compreensão do movimento de significação e de articulação da linguagem em ambientes de troca e cultura informacional a partir de uma perspectiva semiótica.

\begin{tabular}{|c|c|c|c|}
\hline \multicolumn{4}{|c|}{ TRÊS MANEIRAS DE VER O MUNDO } \\
\hline $\begin{array}{c}\text { PERTO } \\
\text { DEMAIS }\end{array}$ & SENSAÇÃO & PRIMEIRIDADE & ACORDO TÁCITO \\
\hline $\begin{array}{c}\text { MAIS OU } \\
\text { MENOS } \\
\text { PERTO }\end{array}$ & AÇÃOE & SECUNÃO & ACORDO \\
\hline LONGE & RAZÃO & TERCEIRIDADE & ACORDO ONTOLÓGICO \\
\hline
\end{tabular}

Quadro 2 - Três maneiras de ver o mundo.

Ao compreender a questão informacional dessa perspectiva, sugerimos a coexistência de uma tríade de acordos no nível da linguagem que é adotada em ambientes digitais com propósitos de organização e recuperação de informações. São eles: o tácito, o semântico/semiótico e o ontológico. 


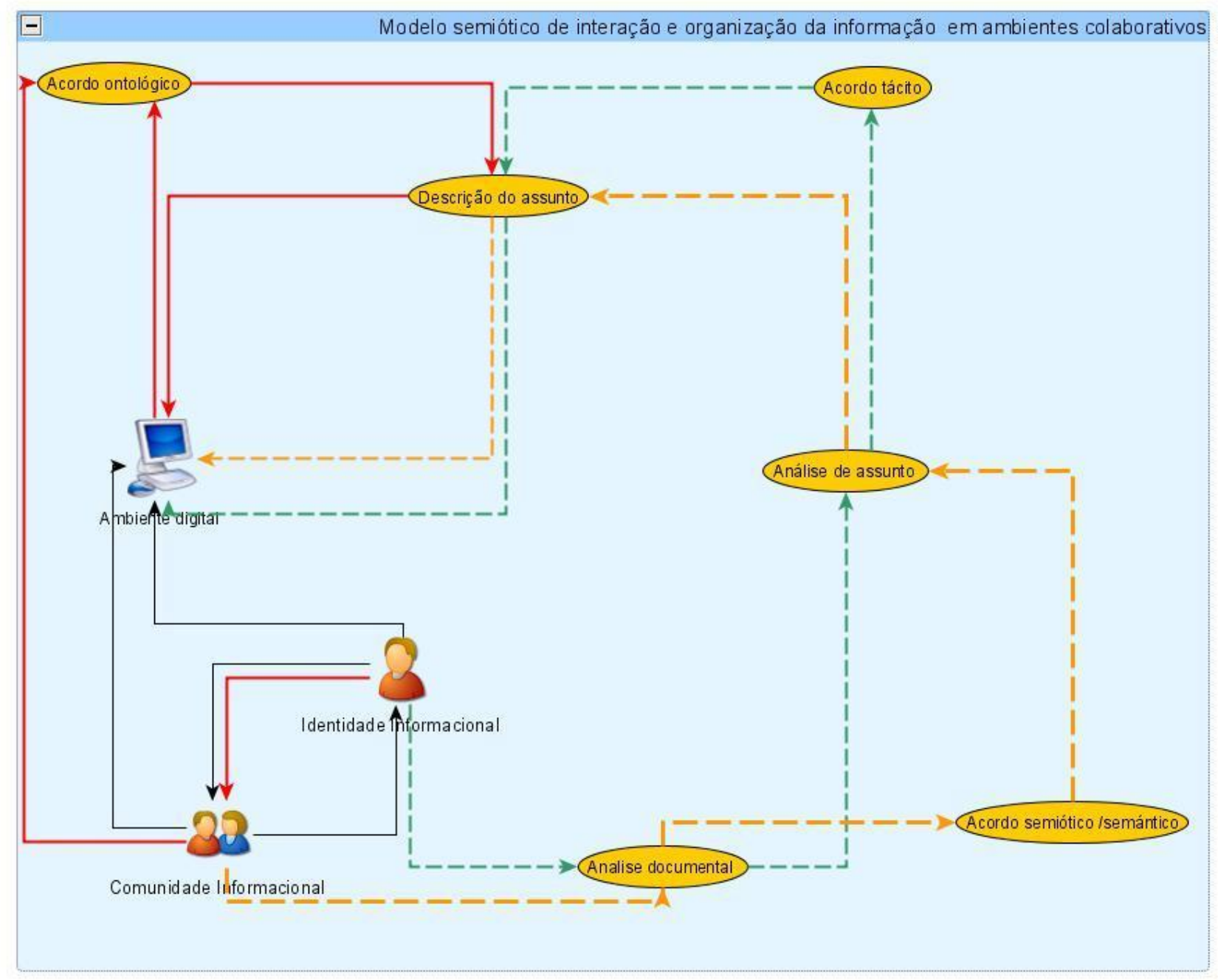

Figura 5 - Modelo semiótico de interação e organização da informação em ambientes colaborativos.

O acordo tácito é revelado na indexação individual realizada pelas identidades informacionais em ambientes colaborativos. À semelhança da perspectiva egocêntrica, não há nesse acordo uma preocupação como a perenização das representações, mas com o desenvolvimento de um apoio à memória de curto prazo do usuário. Como o passar do tempo, o acordo que é estabelecido entre essas distintas identidades informacionais passa a nortear as ações desses sujeitos em alguns mecanismos colaborativos de representação da informação, dando início a um segundo nível de acordo de significação/representação.

O acordo semântico/semiótico ocorre em ambientes de troca e cultura informacional. O estabelecimento dessa modalidade de acordo leva em consideração os interesses pactuados no âmbito desses espaços, sejam eles efêmeros ou perenes. Podese afirmar que essa modalidade de acordo, por se inspirar na sobreposição de garantias 
(literária $^{5}$, de uso $^{6}$ e estrutural ${ }^{7}$ ) acaba por fornecer um nível de estabilidade e regularidade na linguagem permitindo a melhoria da performance na recuperação da informação. Isso se deve à manutenção colaborativa de um sistema simbólico de referência.

O acordo ontológico configura-se como uma tendência de monitoramento das práticas colaborativas na Web. Busca-se na efetividade dessa modalidade de acordo a constituição de uma sobreposição de signos que sejam compreensíveis/legíveis tanto para os seres humanos quanto para os dispositivos tecnológicos. Nesse sentido, o monitoramento das práticas colaborativas na web levaria à consolidação de ontologias gerais e de domínio mais conexas às trocas e demandas efetivas de agentes humanos em cooperação.

\section{CONSIDERAÇÕES FINAIS}

O modelo de fluxo da informação apresentado nesse estudo buscou compreender os movimentos em prol do estabelecimento de regularidades no tratamento temático da informação em ambientes digitais.

Em termos pedagógicos, assinalamos que o ambiente digital, colaborativo ou não, interpõe de modo contínuo e indiscriminado os sujeitos e suas redes de interação, os documentos, os espaços de troca e cultura informacional (um correlato do que Tim O' Reilly chamou de arquitetura da participação), os produtores de conteúdos e os espaços dedicados ao processamento de acordos, ao cotejamento, à sistematização e à experimentação de linguagens de referência.

Nesse sentido, buscamos assinalar, como apontam os estudos realizados por Yunta (2009) e Spiteri (2007), o caráter urgente de se incorporar em nossa agenda de pesquisa o estudo desse fenômeno informacional em suas dimensões sociais e técnicas, com vistas a qualificar as nossas reflexões e as mediações informacionais delas decorrente.

\footnotetext{
${ }^{5}$ Um conceito introduzido por Wyndam Hulme em 1911, baseia-se na idéia de que a linguagem de representação da informação deve tomar por referência textos canônicos da disciplina ao qual se destina o instrumento ou um conjunto de documentos determinados pela freqüência de citação na disciplina.

6 Baseia na incorporação crítica da linguagem de referência adotada pelos usuários em situação de interação com o sistema de informação. Essa incorporação pode contribuir no repertório das relações associativas e dos sinônimos.

${ }^{7}$ A garantia estrutural admite a incorporação de termos que, embora não presentes na literatura e nas expressões de busca do usuário, são úteis para tornar a estrutura da linguagem funcional. Os termos estruturais permitem suprir links esquecidos na estrutura hierárquica e a incorporação de um conjunto de termos mais específicos em uma linguagem em crescimento.
} 
Como resultado da análise efetuada, cabe indagar sobre o futuro da organização da informação em ambientes colaborativos. Indubitavelmente a personalização tecnológica permitida pelo advento da Web 2.0 contribuiu significativamente no avanço e atualização dos instrumentos reguladores dos processos de organização da informação, no entanto ainda resta compreender, nesse contexto, os fatores intervenientes representados pela configuração de identidades informacionais, não mais apreensíveis por sistemas calcados apenas em dispositivos presenciais.

Hoje, é possível afirmar que os objetos e os sujeitos convivem no ambiente digital, sob a forma de fluxos informacionais e que tais transformações demandam alterações nos processos formativos dos profissionais da informação. Além disso, as mudanças na forma de organização e disseminação da informação exige uma postura pró-ativa da parte da $\mathrm{Cl}$ no que concerne à formação do usuário que indexa e disponibiliza autonomamente seus conteúdos em sistemas de informação cooperativos e abertos. Assumir o desenvolvimento do tagging literacy, como uma dimensão da cultural informacional contemporânea, proporcionará mais efetividade às reflexões, aos produtos e aos serviços desenvolvidos sob a perspectiva da Ciência da Informação.

Conforme pudemos notar ao longo desse trabalho, muitos têm sido os esforços, em termos metodológicos, no sentido de incorporar a dinamicidade inerente aos novos instrumentos de circulação da informação e do saber. $O$ uso social outorgado pelos sistemas de classificação distribuídos (DCSs) e a potencialidade dos mesmos em contribuir para a efetivação de sistemas informacionais modelados de um ponto de vista semiótico, assinalam que o futuro dos estudos no campo da organização da informação e do conhecimento deverá compreender as questões do usuário, agora na condição de ator central na especificação e gestão de seus perfis e necessidades informacionais.

\section{AGRADECIMENTOS}

Agradecimentos são devidos ao CNPq pelo apoio concedido no desenvolvimento deste trabalho. Agradeço igualmente aos bolsistas de iniciação científica que integraram as distintas etapas da pesquisa "Semiótica, informação audiovisual e percurso interpretativo: bases teóricas para organização da informação em contextos digitais", Juliana de Assis Horta, Rubeniki de Limas, Roberta Peçanha de Carvalho Gomes e Tânia Renata dos Santos. 


\section{REFERÊNCIAS}

CAÑADA, J. Tipologias y estilos en el etiquetado social (2006). Disponível em: <http://www.terremoto.net/tipologias-y-estlos-en-el-etiquetado-social/>. Acesso em: 29 mar. 2009.

GONZÁLEZ DE GÓMEZ, Maria Nélida; GRACIOSO, Luciana de Souza. Ciência da informação e a ação comunicativa no cenário web. In: ENCONTRO NACIONAL DE PESQUISA EM CIÊNCIA DA INFORMAÇÃO, 8., 2007, Salvador. Anais. Disponível em: <http://www.enancib.ppgci.ufba.br/>. Acesso em: 19 fev. 2008.

LANCASTER, F.W. A linguagem natural na recuperação da informação. In: Indexação e resumos: teoria e prática. Brasília: Briquet de Lemos / Livros, $\overline{1993 . ~ p . ~} 200$ 28.

LEMOS, André. Cibercultura: técnica, sociabilidade e civilização do virtual. In: PRETTO, Nelson de Luca (Org.). Globalização \& Educação: mercado de trabalho, tecnologias de comunicação, educação a distância e sociedade planetária. ljuí: Ed. Unijuí, 2000. p. 7897.

MAI, Jens-Erik. The concept of subject in a Semiotic light. Disponível em:<http://www.asis.org/annual-97/mai.htm>. Acesso em: 15 Out. 2008.

MARTELETO, R. M. A metodologia de análise de redes sociais (ARS). In: VALENTIM, Marta Lígia Pomim (Org.). Métodos qualitativos de pesquisa em Ciência da Informação. São Paulo: Polis, 2005. p. 81-100.

MEJIAS, U. A. Tag literacy. Disponível em:

<http://ideant.typepad.com/ideant/2005/04/tag_literacy.html.> Acesso em: 30 mar.2009.

MIKA, Peter. Ontologies are us: a unifed model of social networks and semantics. Disponível em:<http://www.cs.vu.nl/ pmika/research/papers/ISWC-folksonomy.pdf>. Acesso em: 25 maio 2009.

MOURA, M. A. Signi-fica ou signi-vai? As teorias da significação no campo da Ciência da Informação. In: REIS, Alcenir Soares; CABRAL, Ana Maria (Org.). Informação, cultura e sociedade: interlocuções e perspectivas. Belo Horizonte: Novatus, 2007. p. 61-79.

NÖTH, Winfried. Panorama da Semiótica: de Platão a Peirce. São Paulo: Annablume, 1995.

QIN, Jian. Folksonomies and taxonomies where the two can meet. Disponível em: <http://nkos.slis.kent.edu/2008workshop/JianQin.pdf>. Acesso em: 15 set. 2009.

QIN, Jian; CHEN, Miao; LIU, Xiaozhong. Semantic Relation Extraction from SociallyGenerated Tags: A Methodology for Metadata Generation. In: PROC. INT'L CONF. ON DUBLIN CORE AND METADATA APPLICATIONS 2008. Disponível em:

<http://dcpapers.dublincore.org/ojs/pubs/article/viewPDFInterstitial/924/920>. Acesso em: 17 maio 2009. 
QUINTARELLI, E. Folksonomies: power to the people. In: INCONTRO ISKO ITALIA UNIMIB, Milão, 2005. Papers... Milan: Universitá di Milano, 2005. Disponível em:<http://www.iskoi.org/doc/folksonomies.htm>. Acesso em: 18 jul. 2007.

SANTOS, Milton. A natureza do espaço: técnica e tempo. Razão e emoção. São Paulo: Edusp, 2002.

SPITERI, Louise F. Structure and form of folksonomy tags. The Road to the Public Library Cataloque. Webology, v. 4, n. 2, 2007. Disponível em: <www.webology.ir>. Acesso em: 28 nov. 2007.

SVENONIOUS, E. The intellectual foundation of information organization. Cambridge: MIT Press, 2000.

WAL'S, Vander. Folksonomy. Disponível em:

<http://www.vanderwal.net/folksonomy.html>. Acesso em: 20 abr. 2009.

YUNTA, Luis Rodriguez. Etiquetado libre frente a lenguajes documentales: aportaciones en el ámbito de la biblioteconomía Y documentación. In: CONGRESO ISKO ESPANÃ, 9. Papers... Valencia: ISKO, 2009. p. 832-45.

\title{
Title
}

Folksonomies, social networking, and educational development for tagging literacy: challenges for information organization in collaborative virtual contexts

\begin{abstract}
The combined use of social tagging, technological personalization as well as collaborative operations in social networking has brought new challenges to information organization and retrieval in collaborative virtual environments. Basically, these challenges are related changes in the mediation of information organizing and accessing, which are dynamically exerted and shared today by end-users through a set of technological layers. In this article, it is analyzed the social and technical implications of intervenient factors such as the folksonomies and the technological personalization of information organizing of collaborative virtual contexts. The established agreements in the processes of information organization and retrieval in open collaborative contexts are systematized. The concepts of informational identity, Virtual Center for information exchange and informational culture are presented, as well as the concept of tagging literacy which comprehends the user as the most important actor for specifying information needs.
\end{abstract}

\section{Keywords}

Information Organization; Tagging Literacy; Folksonomy; Social Networking; Collaborative Environments.

\section{Título}


Folcsonomías, redes sociales y la formación para el tagging literacy: retos para la organización de la información en ambientes colaborativos virtuales

\section{Resumen}

El uso combinado de sistemas de etiquetaje social (social tagging), de la personalización tecnológica así como del funcionamiento colaborativo en redes sociales trajo nuevos desafíos a la organización y a la recuperación de la información contemporánea en ambientes colaborativos virtuales. Esos desafíos están, sobre todo, en la alteración de la mediación en la organización y acceso a la información, hoy ejercida y compartida de modo dinámico por los usuarios finales por medio de un conjunto de capas tecnológicas. En este artículo, se analizan las implicaciones sociales y técnicas de los factores intervinientes, principalmente las folcsonomías y la personalización tecnológica, en la organización de la información en ambientes colaborativos. Se sistematizan los acuerdos establecidos en los procesos de organización de la información y su recuperación en ambientes colaborativos abiertos. Se presentan los conceptos de identidad informacional, ambientes virtuales de cambios y culturas informacionales y el concepto de cultura clasificatoria (tagging literacy) que comprende las cuestiones del usuario, en la condición de actor principal en la especificación y necesidades informacionales.

\section{Palabras clave}

Organización de la Información. Competencia de la Clasificación. Folksonomía. Redes Sociales. Ambientes Colaborativos.

Recebido em: 26.05.2009

Aceito em: 31.08.2009 